\title{
WASTE MINIMISATION IN INDIAN CONSTRUCTION SECTOR BY APPLYING LEAN MANAGEMENT PRINCIPLES
}

\author{
Devaki M.P. 1, Kaviraj M.S ${ }^{2}$ \\ 1,2Department of Civil Engineering, RVS Technical Campus, Coimbatore, India \\ Email: 1mpdevaki@gmail.com
}

Abstract

The emergence of the lean construction concept is seen as a current approach that can be used to produce best practices because it is viewed as an effort to bring construction industry towards a more optimum productivity level with the efficient usage of resources as well as to produce the utmost value. This study aims to advance knowledge on construction site waste minimization through the application of lean principles. The objectives of the study include the identification of sources and causes of wastes in construction in Indian construction industry, analysis of the waste to categorize and prioritize it and suggestions of Lean principles to minimize the wastes.

Key words: Waste minimization, Lean Management, Indian Construction sector

\section{I.INTRODUCTION}

India's rapid economic growth over the last decade has placed tremendous stress on its limited infrastructure. The construction industry is one of the largest industries that support the economy of every country in the world. Past research into the causes of waste in construction projects indicate that waste can arise at any stage of the construction process from inception, right through the design, construction and operation of the built facility. Waste in the construction industry has been the subject of several research projects around the world in recent years your paper here.

In the past few decades, great performance improvements have been obtained in the manufacturing industry by means of increasing productivity. A major factor in this achievement was the implementation of the new production philosophy, known as "Lean Production". Lee et al (1999) argues that this approach provides a continuous improvement in the production process by removing various types of wastes. While manufacturing had attained great results, Polat and Ballard (2004) insist that the construction industry still encounters severe problems resulting from huge amounts of waste hence, the need for lean construction to help curb the waste.

Lean Construction is a project management method that helps to minimize waste of materials, time, and effort in order to generate the maximum possible amount of value. Based on the success of Lean Production in manufacturing and the development of Lean Construction in countries such as Brazil, Denmark and the USA, the application of Lean Construction is currently debated in India.

\section{LEAN CONSTRUCTION}

A thorough study of existing data on Lean construction was done to better understand the principles of Lean construction. According to Chick G. et al (2013), waste is more than the physical wastes that are the focus of construction site activity.

\section{A. COMPARISON OF LEAN AND TRADITIONAL CONSTRUCTION}

- Lean Construction is having events to conform to plan while tradition construction is monitoring against schedule and budget projections-tracking.

- Lean looks at optimizing entire project while traditional construction looks optimizing specific activity.

- Lean scheduling is based on pull work schedule based on when its completion is required by a successor activity while traditional scheduling is push scheduling based on emphasizing required start dates for activities.

- Lean measures performance by Percent Plan Complete (PPC) while traditional construction measures by Work Breakdown Structure (WBS), Critical Path Method (CPM) and Earned Value.

- Lean customer satisfaction is succeeding process satisfaction traditional method looks at owner or final consumer satisfaction.

\section{B. PRINCIPLES OF LEAN CONSTRUCTION}

Specify Value - Only what the customer considers as value should be taken into consideration. In construction activities can be classified as 3 types Value Adding (VA), Non-value Adding (NVA) and Necessary Waste (NW). 
Identify the value stream - This is about identifying all the steps in the value stream in order to determine activities that do not add value and seek for their elimination.

Make value flow without interruption - Value should be created in a flow of activities and processes. This is done by minimizing delays, inventories, defects and downtime.

Use pull logistics - All components and information are made and supplied at the necessary time to deliver the product or service to the customer at exactly the time the customer wants it.

Pursue perfection - Lean is about continuously improving through collaboratively identifying and removing waste.

\section{BENEFITS OF LEAN CONSTRUCTION}

Lean construction has many benefits -

- Reduces Waste

- Saves Money and Reduces Cost

- Creates Higher Quality

- Creates Stable Schedules

- Promotes Employee Participation

- Improves Customer Satisfaction

\section{METHODOLOGY}

\section{A. METHOD OF SURVEYING}

A survey was done online to identify the waste generated in construction industry. Out of the 50 companies to which the questionnaire was sent about 33 responded. This is about $66 \%$ which is a good data sample for analysis. The responses were collected from professionals from varied types of organizations and performing different roles and different years of experience. Most of the respondents were architects or civil engineers or senior or middle management who were involved in managing construction projects.

\section{B. RATING SCALE}

A Likert scale of 1-5 was used in the questionnaire. A Likert scale is a type of psychometric response scale often used in questionnaires, and is the most widely used scale in survey research. The questions were constructed using the Likert scale. For example, the respondents were asked to rank on a scale of $1-5$, factors that cause waste on construction sites where $1=$ Never, $2=$ Rarely, $3=$ Sometimes, $4=$ Mostly and $5=$ Always.

\section{STATISTICAL METHOD FOR ANALYSIS OF RESULTS}

Data obtained from the study were ranked according to their mean scores. The mean score is utilized as a measure of central tendency. As stated by Hoe (2006), a high mean relevance rating would mean that the factor under consideration is important. Begum et al. (2006) provides a formula for obtaining the mean score

$$
\mu=\frac{\sum_{\mathrm{i=1}}^{5} i . \mathrm{f}_{\mathrm{i}}}{\sum_{\mathrm{i}=1}^{5} \mathrm{f}_{\mathrm{i}}}
$$

Where, $f$ is the frequency of score $i$ for the factor concerned.

Table 1. Analysis of data on causes of waste - design

\begin{tabular}{|l|c|}
\hline \multicolumn{1}{|c|}{ Design } & $\begin{array}{c}\text { Mean } \\
\text { Score }\end{array}$ \\
\hline Frequent design changes & 3.36 \\
\hline Delay in approval of drawings & 3.33 \\
\hline Lack of design information & 3.09 \\
\hline Design defects and errors & 2.9 \\
\hline Contradictions in design documents & 2.9 \\
\hline
\end{tabular}

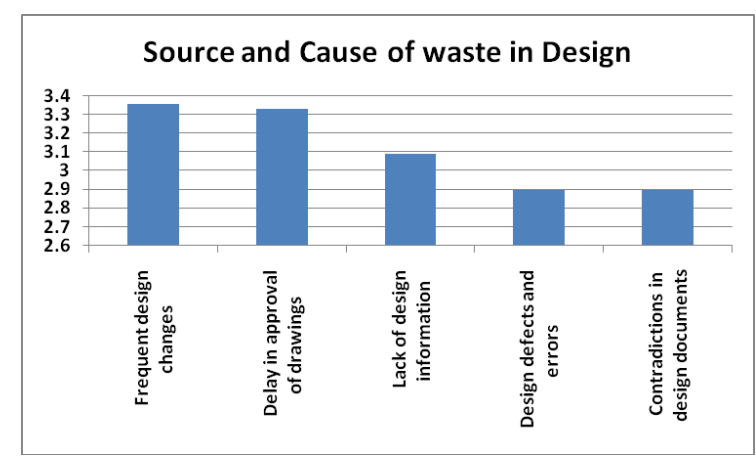

Fig. 1. Barchart representing the surveyed source and cause of waste in design

The analysis on source and causes of waste during design revealed that major source of waste was due to

- Frequent design changes

- Delay in approval of drawings

- Lack of design information

Frequent design changes lead to waste in material because of the old material which has been ordered not conforming to the new design and standards. It also results in waste of effort because of the work which has already been put in. Waste of money and time also result because of the constant changes. 
Delay in approval of drawings results in delay in work starting and wastage of resources and wastage of their time. The delay will also result in delay of the work completion and results in lots of waste.

Lack of design information in the form of incomplete data can lead to ordering of materials which do not meet the specifications, and which in turn leads to wastage of material. Incorrect or incomplete information can lead to work not being done up to standards and later result in rework resulting in waste of time and effort.

Table 2. Analysis of data on causes of waste - procurement

\begin{tabular}{|l|c|}
\hline \multicolumn{1}{|c|}{ Procurement } & $\begin{array}{c}\text { Mean } \\
\text { Score }\end{array}$ \\
\hline Delay in material supply & 3.09 \\
\hline Over-ordering/under-ordering materials & 2.81 \\
\hline $\begin{array}{l}\text { Delay in transportation/installation of } \\
\text { equipment }\end{array}$ & 2.78 \\
\hline $\begin{array}{l}\text { Ordering materials not matching } \\
\text { requirements }\end{array}$ & 2.48 \\
\hline
\end{tabular}

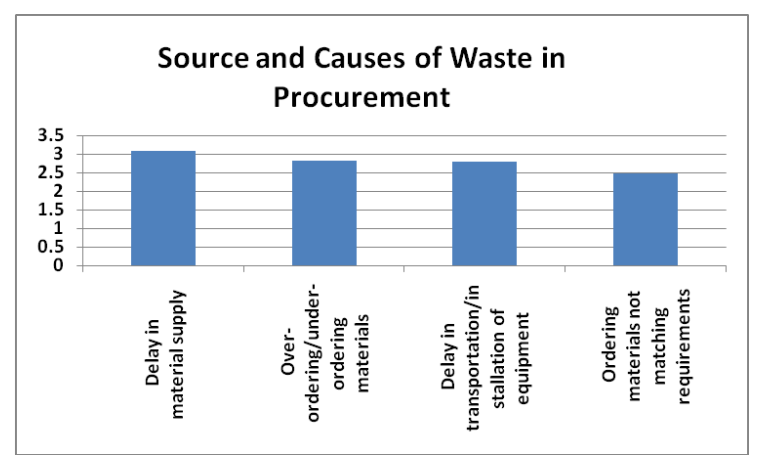

Fig. 2. Barchart representing the surveyed source and cause of waste in procurement

The analysis on source and causes of waste during procurement revealed that major source of waste was due to

- Delay in material supply

- Over ordering /Under ordering of materials

Delay in material supply is a major risk especially when the Lean principle advocates just in time supply. The delay in supply can have cascading affect as this can result in resources sitting idle which will result in delay in the project which results in waste of time and effort of resources and money. Proper material management with proper management of the supply chain is necessary to result in waste minimization.
Over-ordering of materials can lead to waste of money and waste of material also it results in wastage of storage area. Lot of effort is also wasted in the keeping of inventory of material which ultimately may not be utilized. Lean management suggest just in time supply of materials though it involves lot of risk but with proper material management and inventory control the waste can be minimized to a great extent.

Under-ordering of materials can also lead to resources sitting idle and waiting for material. This results in waste of time and resources. This can be effectively controlled by proper material management and proper inventory control.

Table 3. Analysis of data on causes of waste material handling

\begin{tabular}{|l|c|}
\hline \multicolumn{1}{|c|}{ Material handling } & $\begin{array}{c}\text { Mean } \\
\text { Score }\end{array}$ \\
\hline $\begin{array}{l}\text { Damage of materials due to } \\
\text { improper storage }\end{array}$ & 2.93 \\
\hline Lack of Onsite material control & 2.93 \\
\hline $\begin{array}{l}\text { Delay due to unorganized material } \\
\text { storage }\end{array}$ & 2.84 \\
\hline
\end{tabular}

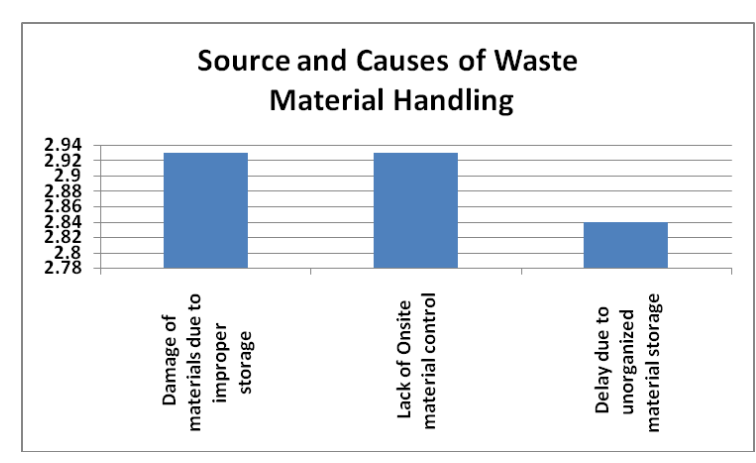

Fig. 3. Barchart representing the surveyed source and cause of waste in material handling

The analysis on source and causes of waste during material handling revealed that the major sources were

- Damage due to improper storage

- Lack of material control/management

Proper storage facilities for materials are a must to ensure that the materials which have been ordered do not get damaged and cause waste of money and material. Practitioners generally overlook the storage facilities thinking it will be an investment but this one time investment can go a long way in ensuring waste minimization and money loss due to materials being damaged. 
Material management and control is a must to ensure that materials which have been bought are used for their purpose and there is no unnecessary waste of material and also the waste which is generated how it can be recycled.

Table 4. Analysis of data on causes of waste - operations

\begin{tabular}{|l|c|}
\hline \multicolumn{1}{|c|}{ Operations } & $\begin{array}{c}\text { Mean } \\
\text { Score }\end{array}$ \\
\hline Lack of waste management plans & 3.30 \\
\hline Lack of coordination among crews & 3.18 \\
\hline Slow decision making & 3.12 \\
\hline Unrealistic Master schedule & 3.03 \\
\hline Poor site management & 2.90 \\
\hline Non-participative nature of management & 2.90 \\
\hline Rework due to workers mistakes & 2.90 \\
\hline Poor planning and coordination & 2.84 \\
\hline Scarcity of crews & 2.84 \\
\hline $\begin{array}{l}\text { Waiting for design documents and } \\
\text { drawings }\end{array}$ & 2.63 \\
\hline Scarcity of equipments & 2.54 \\
\hline Choice of wrong construction method & 2.39 \\
\hline Accidents due to lack of safety & 2.30 \\
\hline
\end{tabular}

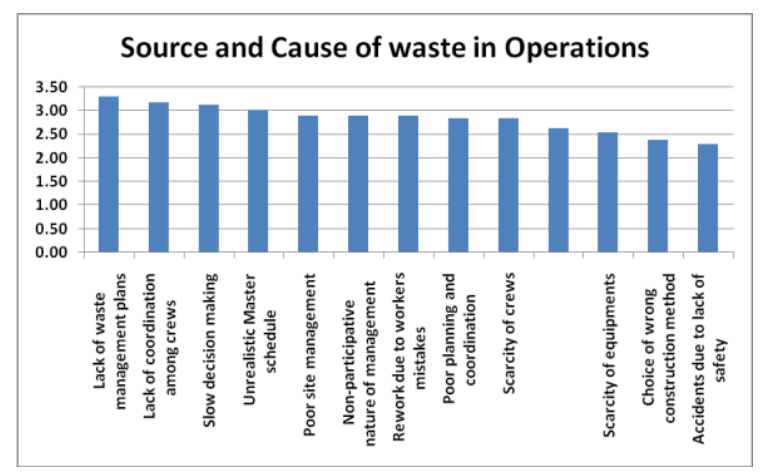

Fig. 4. Barchart representing the surveyed source and cause of waste in operations

The analysis on source and causes of waste during operations revealed that major source of waste was due to

- Lack of waste management plans

- Lack of coordination among crew members

- Slow decision making

- Unrealistic master schedule

- Non participative style of management

- Poor site management
During construction lot of waste is generated. Materials waste which is generated can be effectively sorted and recycled and reused .If proper waste management plan is present then this is an organized and easy task if not then the waste is not collected ad stored and can get damaged. Planning for waste management can reduce waste to a large extent.

Lack of coordination among crew members is another reason for waste generation. Construction involves a large number of crew members. These people work as groups like masons, carpenters, electricians, etc. Generally one group does not know what the other is doing. If one group is delayed other needs to sit idle if things are not known or planned ahead.

Slow decision making is another source for waste in time and effort for resources as resources will need to sit idle until decision is made. If work is done before a decision is taken it can result in rework and again waste is generated. This generally happens where the work is done in a hierarchical management system where all decisions need to be approved by management before the workers can work.

Unrealistic master schedule which has been prepared during the planning phase by the managers and planners to the detail can be quite an overload for workers. The project control which is done using this schedule can lead to overwork and underperformance. This is generally done in the tradition project management where all the activities are planned during the planning phase and a detailed master schedule is prepared and during the actual construction project is controlled activity wise based on the start and end date on the schedules. Any unforeseen circumstances can seriously undermine these master schedules as it has been prepared during start of the project.

Non participative style of management can result in people being not being motivated not performing according to their capabilities this can result in substandard quality of work as the workers do not feel a sense of ownership or satisfaction for the work they do. In this method the workers merely perform as per orders. In participative management the workers also take part in decision making and feel a sense of ownership and so the quality of work is better. Also the worker helps to bring to the table issues which is actually faced on the ground and also the ground and day to day experience of workers will help is formulating simple solutions to complicated issues.

Poor site management can lead to waste generation. This can lead to accidents which in turn lead to delay in project, resource effort and attention being diverted, lot of 
money being spent on insurance and welfare measures. So this can lead to waste of effort, time and money. Also improper site management can result in material wastage. Also lot of effort will be wasted searching for material equipment and things. Proper and clean site will result in work being done fast and in time and safely.

\section{RECOMMENDATIONS AND CONCLUSIONS}

Work due to frequent design changes can be minimized to a great extent using BIM Building Information Modeling (BIM) a visualization tool used to build a building virtually, prior to building it physically, in order to work out problems and simulate and analyze potential impacts.

Procurement issues can be minimized by choosing proper suppliers and Establish strategic alliances with them. Also to minimize these issues, Lean suggests standardizing and industrializing by prefabrication. Participative style of managing projects and Just-in-time ordering also helps to minimize waste due to procurement

Not over-ordering, using $5 \mathrm{~S}$ lean method of sort straighten, shine standardize and sustain helps in material handling waste minimization. Increased visualization which involves communicating key information effectively to the workforce through posting various signs and labels around the construction site also contributes to minimize waste.

Wastes generated during actual construction can be minimized to a great extent by using the Last planner tool suggested by Lean. The current planning system in the construction industry is a push system. The process is such that work is done in order to comply with the budget and schedules already made, and the belief that providing the sufficient amount of resources is enough to ensure competition of task in the desired time and quality.

The Last Planner System replaces optimistic planning with realistic planning based on the last planners' ability to achieve their commitments. Last planners are usually foremen or site supervisors who decide what work is to be done the following day. In this system first a master schedule is prepared with milestones. Then next step is to take each mile stone as a phase and produce a phase wise schedule. The schedule helps for look ahead planning which helps supervisors to decide what is to be done in near future to remove constraints for activities scheduled ahead. Then weekly and daily plans are made which can help to generate metrics of percentage of planned work completed.

\section{ACKNOWLEDGEMENT}

We record our gratitude to the professionals who took time off from their busy schedules to complete the questionnaire survey.

\section{REFERENCES}

[1] Lee, S., Diekmann, I. E., Songer, A. D., and Brown, H. (1999), 'Identifying Waste: Applications of Construction Process Analysis', Proceedings IGLC-7, University of California, Berkeley, California, USA.

[2] Polat, G. and Ballard, G. (2004), 'Waste in Turkish Construction- Need for Lean Construction Techniques', Proceedings of the 12th Annual Conference of the International Group for Lean Construction IGLC-12, Denmark

[3] Chick, G., Corfe, C., Dave, B., Fraser, N., Kiviniemi, A., Koskela, L., O'Connor, R., Owen, R., Smith, S., Swain, B. and Patricia Tzortzopoulous (2013), Implementing lean in construction, CIRIA, London, United Kingdom.

[4] Hoe, L.K. (2006), Causal model for management of subcontractors in waste minimization, Unpublished Ph.D. thesis, Department of Building, National University of Singapore.

[5] Begum, R.A., Siwar, C., Pereira, J.J. and A.H. Jaafar (2006), 'Implementation of waste Management and minimization in the Malaysian construction industry', Conservation and $\begin{array}{llll}\text { Recycling, } & 51, & \text { pp. } & 190-202\end{array}$ 